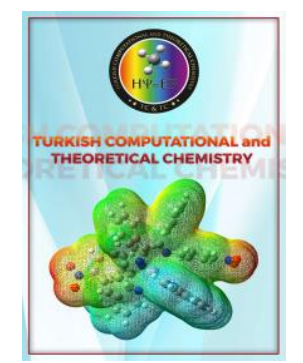

Received: 20.02 .2020
Turkish Computational and Theoretical Chemistry

Turkish Comp Theo Chem (TC\&TC)

Volume(Issue): 4(1) - Year: 2020 - Pages: 39-48

e-ISSN: 2602-3237

https://doi.org/10.33435/tcandtc. 691754

Accepted: 05.06.2020



Research Article

\title{
A DFT Study of Si Doped Graphene: Adsorption of Formaldehyde and Acetaldehyde
}

\author{
Ozge AKYAVASOGLU ${ }^{\text {a, }}$ M. Ferdi FELLAH ${ }^{1, a}$ \\ ${ }^{a}$ Department of Chemical Engineering, Bursa Technical University, Mimar Sinan Campus, 16310, Bursa, \\ Turkey
}

\begin{abstract}
In this study, Si doped graphene sensor property for indoor volatile contaminants formaldehyde and acetaldehyde has been examined. The B3LYP hybrid method with 6-31G(d,p) basis set has been used for this purpose. The adsorption energy of formaldehyde and acetaldehyde have been found to be -24.5 and $-33.3 \mathrm{kcal} / \mathrm{mol}$, respectively. The characteristic $\mathrm{C}=\mathrm{O}$ bond frequency has been decreased after adsorption of the molecules and the bond peaks frequencies have been decreased in both aldehydes. There was a charge transfer from adsorbent to formaldehyde oppositely from acetaldehyde to adsorbent.
\end{abstract}

Keywords: Adsorption, Formaldehyde, Acetaldehyde, DFT, Graphene, Si doping

\section{Introduction}

Graphene is a carbon sheet in a hexagonal lattice [1]. It is preferable due to electrical conductivity, thermal conductivity, structural flexibility, ultrathin thickness, high surface-tovolume ratio and chemical stability [2]. Contrary to these advantages, the lack of functional groups, band gap energy and being not producible in large amount makes graphene inconvenient to be used in the application of gas/vapor adsorption. Some methods such as doping, hybridization and functionalization, etc. have been used to increase the performance of the element in this process. [3]. Doping of graphene with many atoms such as sulfur and boron, etc. have been studied for different applications. [4] Silica (Si) can be preferable as dopant of graphene for gas adsorption since there is a strong interaction [5]. Si doped graphene was investigated for the adsorption of $\mathrm{NO}[6], \mathrm{N}_{2} \mathrm{O}[6]$, $\mathrm{NO}_{2}[1,6,7], \mathrm{CO}[1,2], \mathrm{H}_{2} \mathrm{O}[1]$ and $\mathrm{O}_{2}[1,8]$ in literature.

There are many pollutants such as formaldehyde, and acetaldehyde, in both indoor and outdoor [9]. These volatile organic compounds are vaporized at room temperature and breathed [10] for that reason damages of these pollutants on human health should be considered [11]. The indoor source and their health effects are

\footnotetext{
${ }^{1}$ Corresponding Authors

e-mail: mferdi.fellah@btu.edu.tr,mffellah@gmail.com
}

summarized in Table 1. Determination of concentration of these compounds in the air is very critical [12].

There have been many studies about formaldehyde adsorption on graphene. In Majidi et al. 's [13] paper, low binding energy, large adsorption distance and small charge transfer in formaldehyde adsorption on graphene were obtained. Hence, researcher focus on doped graphene to increase adsorption efficiency. It was seen that $\mathrm{Si}, \mathrm{Cr}$ and $\mathrm{Au}$ doped graphene adsorbed formaldehyde very strongly while $\mathrm{N}$ and B doped graphene structures did not [14]. It is approved that Al [14], Mn [14] and Si [15] doped graphenes are very effective on formaldehyde sensing. Also, in Zhou et al. [16] study, it is noted. The adsorption can be strengthed with formation vacancy in graphene structures.

Formaldehyde was adsorbed on Graphene-like Boron Nitride with pseudo-second-order model [17]. In Wang et al.'s study [18]; it was shown that adsorption efficiency of formaldehyde onto $\mathrm{GO} / \mathrm{SnO}_{2}$ is higher than the bare GO. It was also determined that toluene took precedence over formaldehyde on co-adsorption of toluene and formaldehyde on metal basic zeolite [19]. 
Table 1. Formaldehyde and acetaldehyde source and health hazard

\begin{tabular}{lll}
\hline Pollutant & $\begin{array}{l}\text { Example } \\
\text { Source }\end{array}$ & Health Hazard \\
Formaldehyde & $\begin{array}{l}\text { Resin, } \\
\text { binder, } \\
\text { paper, paint }\end{array}$ & $\begin{array}{l}\text { poisoning, } \\
\text { allergy, asthma, } \\
\text { pulmonary } \\
\text { [2] wood, } \\
\text { damage, cancer }\end{array}$ \\
& $\begin{array}{l}\text { cosmetic, } \\
\text { textile [3] }\end{array}$ & \\
Acetaldehyde & $\begin{array}{l}\text { Adhesive, } \\
\text { nail polish }\end{array}$ & pulmonary \\
damage, \\
[5] Alcohol, \\
narcosis, cancer \\
fermented \\
food, \\
cigarette, \\
exhaled \\
gases [6] \\
deodorant \\
[7]
\end{tabular}

It was reported in the investigation GrapheneTungsten trioxide for acetaldehyde adsorption that the ratio Graphene/Tungsten was main parameter for gas sensing property [20]. In DFT study of acetaldehyde adsorption on gold, there was no any significant position of acetaldehyde for adsorption on $\mathrm{Au}[21]$.

In present work, formaldehyde and acetaldehyde adsorption on Si doped graphene has been studied and sensor property of $\mathrm{Si}$ doped graphene for contaminants has been investigated theoretically. DFT-B3LYP method with $6-31 G(d, p)$ basis set have been used for this purpose.

\section{Computational Method}

Structure of $\mathrm{Si}$ doped graphene will be determined with based on DFT (Density Functional Theory) [22,23] which is one of the quantum chemical calculation methods according to scope of the study. The Gaussian 09 software [24] was run for the B3LYP method from DFT calculations. This method will be run in the quantum chemical calculations to be conducted within the scope of the project. The B3LYP method is actual hybrid DFT method using Becke's triple parameter [25]. The functional hybrid B3LYP has become prominent with its the cost of calculation, the coverage and the accuracy of the results. It is very common method for organic chemistry researches. [26,27]. The basis set to be used for the elements are 6-31G $(\mathrm{d}, \mathrm{p})$, which is mostly used in quantum chemical calculations in the literature [28-30]. Also, Van der
Waals corrections can also be used to provide the most commonly used ab-initio molecular dynamics (AIMD) In addition, depending on the changing thermodynamic conditions and the variety of reactions occurring, Van der Waals corrections can also be used to provide usually, used ab-initio molecular dynamics (AIMD) [31]. Hence, graphene can be synthesized in practice as a monolayer, graphene structures will be protecting as monolayer with quantum chemical calculations on it. The doping process will be performing on the carbon vacancy that is formed conveniently on the graphene surface. Figure 1a shows the monolayer graphene structure used in this study.

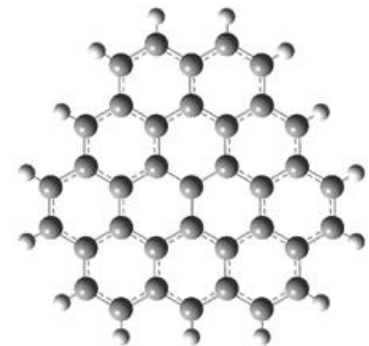

(a)



(b)
Figure 1. a) Pure Graphene Structure b) Sidoped Graphene Structure

The theoretical calculations used by DFT method for both cluster model and periodic structures generally give very close trends for the structural parameters and reactivity $[32,33]$. Ricca et al. [34] have been studied on B and $\mathrm{N}$ co-doped graphene structure by both periodic and cluster approaches. It has been confirmed similar structural properties for both approaches. Additionally, the cluster models were used to form a quality image at molecular level for furfural adsorption on Pt doped graphene [35]. The complexes adsorbed on clusters gave very similar adsorption energy (within the $1.2 \%$ range for electronic energy) and geometrical properties (as example: $1.952 \AA$ and $1.951 \AA$ for Pt$\mathrm{C}$ atoms respectively) on both small cluster $\left(\mathrm{PtC}_{72} \mathrm{H}_{21}\right)$ and large cluster $\left(\mathrm{PtC}_{180} \mathrm{H}_{33}\right)$ [32]. Also, in a theoretical work [36] which is a comparative study of cluster and supercell approaches for the reaction $\mathrm{N}$ and $\mathrm{H}$ to $\mathrm{NH}$ on $\mathrm{Ru}(0001)$ surface it has been reported that a periodic supercell approach adopted plane waves and density functional methods reveals similar barriers for reaction. Thus, in this study Si-doped graphene structure has been simulated by the cluster modeling approach.

A monolayer graphene structure includes 37 carbon atoms and 12 honeycomb rings to be employed within the scope of the research is seen. It has been reported in experimental and theoretical studies that elements have been mostly doped into hexagonal (honeycomb ring) structure of the 
graphene and accomplished results have been get [37-39]. Therefore, the structure where the element doping takes place was desired a hexagonal (honeycomb) ring. As shown in the Figure 1, instead of the carbon in the honeycomb ring in the center, the atom $\mathrm{Si}$ is substituted. The free bonds of the last carbon atoms are saturated with hydrogen atoms (15 in total). In cluster modeling, saturation with hydrogen is fulfilled so that the atoms remaining at the end are not charged. Due to the graphene studies, which are doped with basic elements, this model seems to be proper, since the cluster approach is preferable to the periodic approach and the selected cluster size is adequate for the accuracy of the studies [40,41].

After the optimized geometry of the designed structure, formaldehyde adsorption was then performed. In addition, acetaldehyde adsorption on Si-doped graphene structure having the same dimension and acetaldehyde adsorption on Sidoped graphene structure will be made and compared.

The geometry optimized by doping $\mathrm{Si}$ atom to graphene structure and adsorption of formaldehyde and acetaldehyde on it will be brought to the most suitable geometry with (EG) Equilibrium Geometry calculation. EG calculations were used to optimize the geometries of the structures and to obtain the adsorption energies. In this study, energy difference values contain ZPE (Zero Point Energy) corrections. These energies were obtained using frequency expression in SPE (Single Point Energy) calculations after determine optimized structure. Besides, thermal enthalpy, vibration frequency, Gibbs free energy and energy values were obtained by SPE calculations under standard conditions in Gaussian software [42]. The indicated energy values were obtained for formaldehyde and acetaldehyde adsorption to the Si-doped graphene structure having the next formulas.

$$
\begin{gathered}
E=E_{\text {electronic }}+Z P E+E_{\text {vibrational }}+ \\
E_{\text {rotational }}+E_{\text {tanslational }} \\
H=E+R T \\
G=H+T S
\end{gathered}
$$

$\mathrm{E}$ is the sum of electronic energies, thermal energies and ZPE. $\mathrm{H}$ is the sum of enthalpy and thermal energies, $G$ is the sum of electronic free energy and thermal enthalpy, $\mathrm{T}$ is the temperature, $\mathrm{S}$ is entropy and $\mathrm{R}$ is the ideal gas constant value applied for the vibration frequency calculations. The scaling factor [40] was used as 0.9613 for each vibration frequencies for continuous renewal of the experimental foundations. The HOMO and LUMO energy values were obtained up to all optimized geometries. Some values were used to get information about optimized structures using HOMO LUMO values. The following equations were derived to comment on the activity of the graphene structure, electrophilicity, electronegativity, chemical hardness and chemical potential, values were obtained. $\epsilon \mathrm{HOMO}$ is the highest occupied molecular orbital energy and $\epsilon$ LUMO is the lowest un-occupied molecular orbital energy. The basis of these equations is Koopman's approach [43-45] are as next.

Chemical hardness $(\eta)=\frac{I-A}{2}$

Chemical potential $(\mu)=-\frac{I+A}{2}$

Electronegativity $(\lambda)=-\mu$

Electrophilicity $(\omega)=\frac{\mu^{2}}{2 \eta}$

where $I \cong-\epsilon_{\text {Hомо }}$ and $A \cong-\epsilon_{\text {LUMO }}$

The SM (spin multiplicity) of the cluster and of the adsorbing molecule was obtained as a theoretical approach using SPE calculations. The SPE values of the systems were set using different SM values. In accordance with the results obtained, the SM value giving the lowest energy was accepted as the SM required for the system since the lowest energy state of the systems was considered the most stable state. The Si-doped graphene structure and adsorptive molecule were then optimized by EG calculations. Relative energy values were calculated by the following equations.

$$
\begin{gathered}
\Delta(E / H / G)=(E / H / G)_{\text {Adsorp-Cluster }}- \\
{\left[(E / H / G)_{\text {Adsorp }}+(E / H / G)_{\text {Cluster }}\right]}
\end{gathered}
$$

Here $\mathrm{E}_{\text {Adsorptive-Cluster }}$ finds the thermal energy of the adsorbent on the doped graphene, the thermal energy of the $\mathrm{E}_{\text {Adsorptive }}$ adsorbing molecule, e.g.. The adsorptive molecule and the $\mathrm{E}_{\text {Cluster }}$ calculate the thermal energy of the first group. In addition, enthalpy $(\Delta \mathrm{H})$ and Gibbs free energy $(\Delta \mathrm{G})$ for acetaldehyde adsorption on $\mathrm{Si}$-doped graphene are calculated.

\section{Results and discussion}

The optimized molecules and $\mathrm{Si}$ doped graphene cluster are shown in Figure 2. The optimized adsorptive molecules angle and bond length before and after adsorption are shown in Table 2. In this study, the $\mathrm{O}=\mathrm{H}$ and $\mathrm{C}-\mathrm{H}$ bonds of formaldehyde were $1.206 \AA$ and $1.110 \AA$, respectively. The most closed values of $1.1 \AA$ and $1.2 \AA$ respectively were reported with B3LYP/LanL2DZ method [46]. The bond angles for $\mathrm{H}-\mathrm{C}-\mathrm{H}$ and $\mathrm{H}-\mathrm{C}=\mathrm{O}$ were computed to be 115.2 ${ }^{\circ}$ and $122.4^{\circ}$, respectively. The $\mathrm{O}=\mathrm{H}$ and $\mathrm{C}-\mathrm{H}$ bonds and $\mathrm{H}-\mathrm{C}-\mathrm{H}$ angle were calculated as $1.1 \AA, 1.1 \AA$ and $115^{\circ} \mathrm{C}$ respectively which were close to 
experimental results [47]. For acetaldehyde molecule $\mathrm{C}=\mathrm{O}, \mathrm{C}-\mathrm{C}$, and $\mathrm{C}-\mathrm{H}$ bond lengths were found as $1.2 \AA, 1.5 \AA$, and $1.11 \AA$ respectively which are well agreement with the literature [48].



(a)



(b)

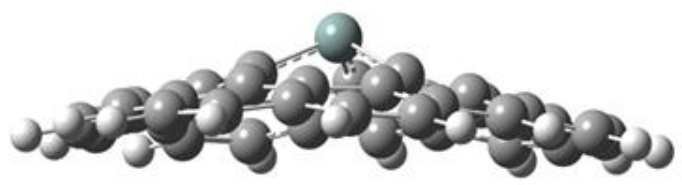

(c)

Figure 2. Optimized structures a) Formaldehyde b) Acetaldehyde c) Top view of $\mathrm{Si}$ doped Graphene c) Side view of Si doped graphene

Table 2. Bond Lengths (Values are in units of $\AA$ )

\begin{tabular}{|c|c|c|c|c|c|}
\hline \multicolumn{2}{|c|}{ Bond } & \multicolumn{2}{|c|}{ Formaldehyde } & \multicolumn{2}{|c|}{ Acetaldehyde } \\
\hline & & $\begin{array}{l}\text { Before } \\
\text { Adsorption }\end{array}$ & After Adsorption & $\begin{array}{l}\text { Before } \\
\text { Adsorption }\end{array}$ & After Adsorption \\
\hline \multirow{6}{*}{ 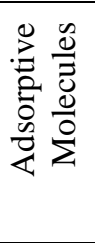 } & $\mathrm{C}=\mathrm{O}$ & 1.20676 & 1.36499 & 1.21072 & 1.37139 \\
\hline & C-H1 & 1.11056 & 1.08318 & 1.11349 & 1.08645 \\
\hline & $\mathrm{C}-\mathrm{C}$ & - & - & 1.51449 & 1.48964 \\
\hline & $\mathrm{C}-\mathrm{H} 2$ & 1.11057 & 1.08565 & 1.09513 & 1.09430 \\
\hline & C-H3 & - & - & 1.09241 & 1.09757 \\
\hline & $\mathrm{C}-\mathrm{H} 4$ & - & - & 1.09513 & 1.10350 \\
\hline \multirow{5}{*}{ 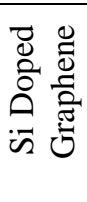 } & $\mathrm{Si}-\mathrm{C} 1$ & 1.77751 & 1.79779 & 1.77751 & 1.80106 \\
\hline & $\mathrm{Si}-\mathrm{C} 2$ & 1.77762 & 1.79728 & 1.77762 & 1.79678 \\
\hline & $\mathrm{Si}-\mathrm{C} 3$ & 1.77766 & 1.79462 & 1.77766 & 1.80207 \\
\hline & $\mathrm{h}$ & 1.61217 & 1.79604 & 1.61217 & 1.70484 \\
\hline & $\mathrm{Si}-\mathrm{O}$ & - & 1.68025 & & 1.67319 \\
\hline
\end{tabular}

Table 3. Adsorption Energies, Enthalpy, and Gibbs free energy (Values are in units of kcal/mol)

\begin{tabular}{cccc} 
& Adsorption Energy & Adsorption Enthalpy & Gibbs Free Energy \\
& $\Delta \mathrm{E}$ & $\Delta \mathrm{H}$ & $\Delta \mathrm{G}$ \\
\hline Formaldehyde & -24.50 & -25.09 & -14.13 \\
Acetaldehyde & -33.32 & -33.91 & -24.00 \\
\hline
\end{tabular}

Geometrical parameters of the optimized Si doped graphene structure before and after adsorption were tabulated in Table 2. Si-C bonds were $1.777 \mathrm{~A}$. Corresponding literature values were reported as $1.765[6], 1.76[49], 1.85[50], 1.772 \AA$ [15] and $1.73 \mathrm{~A}[51,52]$. While $\mathrm{C}=\mathrm{O}$ bond lengths increase $\mathrm{C}-\mathrm{H}$ bond lengths with same $\mathrm{C}$ atoms decrease. Previously it was reported the bond length of $\mathrm{Si}$ and $\mathrm{O}$ atoms of formaldehyde was $1.772 \AA$ which very close our result 1.680 A [15]. The distance between acetaldehyde and doped $\mathrm{Si}$ was calculated as $1.673 \AA$. The characteristic IR peak of aldehydes is for $\mathrm{C}=\mathrm{O}$ bond. In the spectrum $\mathrm{C}=\mathrm{O}$ peak of formaldehyde and acetaldehyde are 1845 $\mathrm{cm}^{-1}$ and $1835 \mathrm{~cm}^{-1}$, respectively. The peaks shifted to $1262 \mathrm{~cm}^{-1}$ and $1284 \mathrm{~cm}^{-1}$ after adsorption, respectively.
The adsorption energy, enthalpy and Gibbs free energy values were shown in Table 3. It could be deduced that the adsorptions occur spontaneously at room temperature. Acetaldehyde adsorption energy is lower than that of formaldehyde as expected [53]. The adsorption energy of acetaldehyde on Si-doped graphene structure was computed to be -33.32 $\mathrm{kcal} / \mathrm{mol}$. This value is somewhat higher than literature values. Previously, the formaldehyde adsorption energy on $\mathrm{Si}$ doped graphene was reported as $-17.7 \mathrm{kcal} / \mathrm{mol}$ [15]. In the other study with aluminum nitride nanotubes the adsorption energy was reported as $-29 \mathrm{kcal} / \mathrm{mol}$ [54]. Acetaldehyde adsorption on $\mathrm{Au}(111)$ surface was $-1.15 \mathrm{kcal} / \mathrm{mol}$ [21]. The adsorption energy of formaldehyde on $\mathrm{Si}$-doped graphene structure was computed to be $-24.50 \mathrm{kcal} / \mathrm{mol}$. Adsorption energy 
of formaldehyde on $\mathrm{Si}$-doped $\mathrm{BC} 3$ sheet was $-26.49 \mathrm{kcal} / \mathrm{mol}$ [16]. Gibbs free energy change for acetaldehyde and formaldehyde adsorptions on Sidoped graphene were calculated to be -24.00 $\mathrm{kcal} / \mathrm{mol}$ and $-14.13 \mathrm{kcal} / \mathrm{mol}$ respectively, these values indicating that acetaldehyde and formaldehyde adsorptions occurs simultaneously on Si-doped graphene.

The Mulliken atomic charges both adoptive and adsorbed molecules are shown in Figure $\mathbf{3}$ and some of them were tabulated in Table 4. The total charge of formaldehyde and acetaldehyde were computed to be $-0.081 \mathrm{e}$ and $0.430 \mathrm{e}$, respectively. Meanwhile, the charge of graphene doped metal and abounded $\mathrm{C}$ atoms after formaldehyde adsorption increased. Oppositely, the graphene charge decreased after acetaldehyde adsorption. It was inferred from the information the charge transfer for acetaldehyde adsorption was from adsorptive to adsorbent but the charge transfer for formaldehyde adsorption was opposite direction. In addition, there is a small charge transfer with formaldehyde as previously reported [13].

The chemical hardness $(\eta)$, the chemical potential $(\mu)$, the electronegativity $(\chi)$, the electrophilicity $(\omega)$ and the energy gap between HOMO and LUMO (HLG) of the Si-doped graphene structure before and after acetaldehyde and formaldehyde adsorptions; HOMO and LUMO energy values were determined. The results obtained are shown in Table 5.

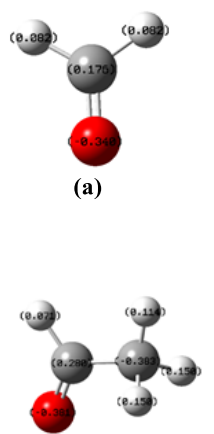

(b)

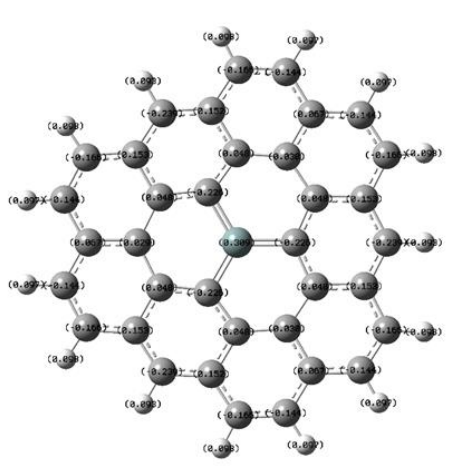

(c)
Figure 3. Atomic charges a) Formaldehyde b) Acetaldehyde c) Si doped graphene

Table 4. Atomic charges of $\mathrm{Si}$ doped graphene clusters (Values are in units of e)

\begin{tabular}{cccc}
\hline Atom & $\begin{array}{c}\text { Before } \\
\text { Adsorption }\end{array}$ & $\begin{array}{c}\text { After } \\
\text { Formaldehyde } \\
\text { Adsorption }\end{array}$ & $\begin{array}{c}\text { After } \\
\text { Acetaldehyde } \\
\text { Adsorption }\end{array}$ \\
\hline 20Si & 0.226 & 0.272 & 0.571 \\
C1 & -0.118 & -0.153 & -0.208 \\
C2 & -0.118 & -0.176 & -0.201 \\
C3 & -0.118 & -0.158 & -0.212 \\
\hline
\end{tabular}

Table 5. Adsorption properties of formaldehyde and acetaldehyde adsorption on Si doped graphene (Values are in units of $\mathrm{kcal} / \mathrm{mol}$ )

$$
\text { Si doped Graphene }
$$

Properties
HOMO Energy
LUMO Energy
HLG

Chemical Hardness

Chemical Potential $((\mu)$

Electronegativity $(\chi)$

Electrophilicity $(\omega)$

$$
\alpha \text { MOs }
$$

$\begin{array}{rr}-98.9 & -128.6 \\ -46.5 & -68.4 \\ 52.4 & 60.2\end{array}$
Formaldehyde Graphene $\alpha$ MOs

$$
-104.1
$$$$
-59.9
$$$$
44.3
$$

82.0

$$
-98.5
$$

101.0

161.0
Acetaldehyde adsorbed on Si doped Graphene $\alpha$ MOs $\quad \beta$ MOs $\beta$ MOs $-121.7$ $-97.4 \quad-121.0$ $-60.0$ $-59.3$ $-59.2$ 61.8 38.1 61.9 30.9 19.1 30.9 78.3 90.1

$\begin{array}{rrr}90.9 & 78.3 & 90.1 \\ -90.9 & -78.3 & -90.1\end{array}$

$\begin{array}{lll}151.9 & 133.7 & 160.9\end{array}$

131.3
The HOMO LUMO Spectrum and images are shown in Figures 4 and 5. For both acetaldehyde and formaldehyde adsorptions on Si-doped graphene structure the HOMO-LUMO gap of $\alpha \mathrm{MOs}$ decreased after adsorptions while a small increase in the HLG of $\beta$ MOs has been observed. In previous studies formaldehyde adsorption on boron nitride nanotubes and Si-doped BC3 sheet, it was reported energy gap change $3.9 \%$ [47] and $28.2 \%$ [16] with mixed orbitals. Additionally, it can be deduced from the following equation that the electrical conductivity of the Si-doped graphene 
cluster increased because of the decrease of the HLG value after adsorption of the acetaldehyde and formaldehyde molecules [54-56].

$\sigma=A T^{3 \prime 2} \exp \left(\frac{-E_{g}}{2 k T}\right)$

where $\sigma$ is electrical conductivity, $\mathrm{A}$ is a constant (electrons $/ \mathrm{m}^{3} \mathrm{~K}^{3 / 2}$ ), for example a cavity of HOMO-LUMO Gap (HLG), T is room temperature and $\mathrm{k}$ is a Boltzmann constant. According to this equation, for a standard temperature, a smaller HLG is a greater electrical conductivity. So far, it has been reported that this relationship agrees well with the experimental results [57]. As a result, adsorption of the acetaldehyde and formaldehyde molecules increase the electrical conductivity of the $\mathrm{Si}$-doped graphene cluster, suggesting that $\mathrm{Si}$ doped graphene may be a potential sensor for the acetaldehyde and formaldehyde molecules.
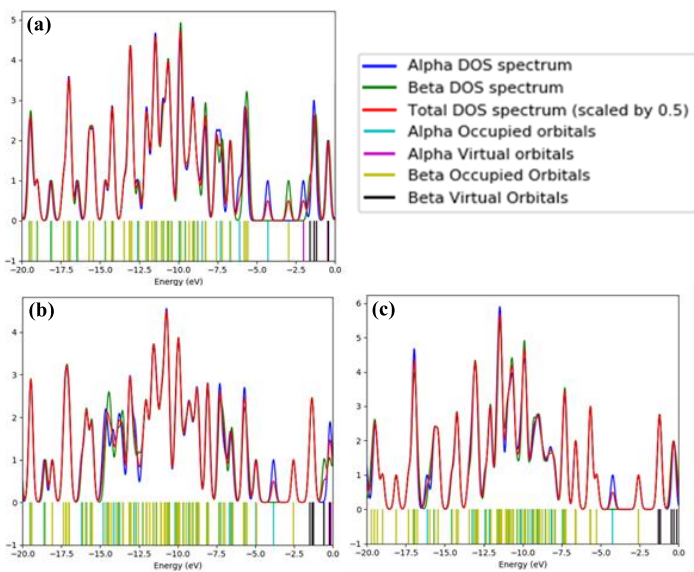

Figure 4. DOS plots a) Si Doped Graphene b) Formaldehyde adsorbed on Si doped Graphene c) Acetaldehyde adsorbed on Si doped graphene

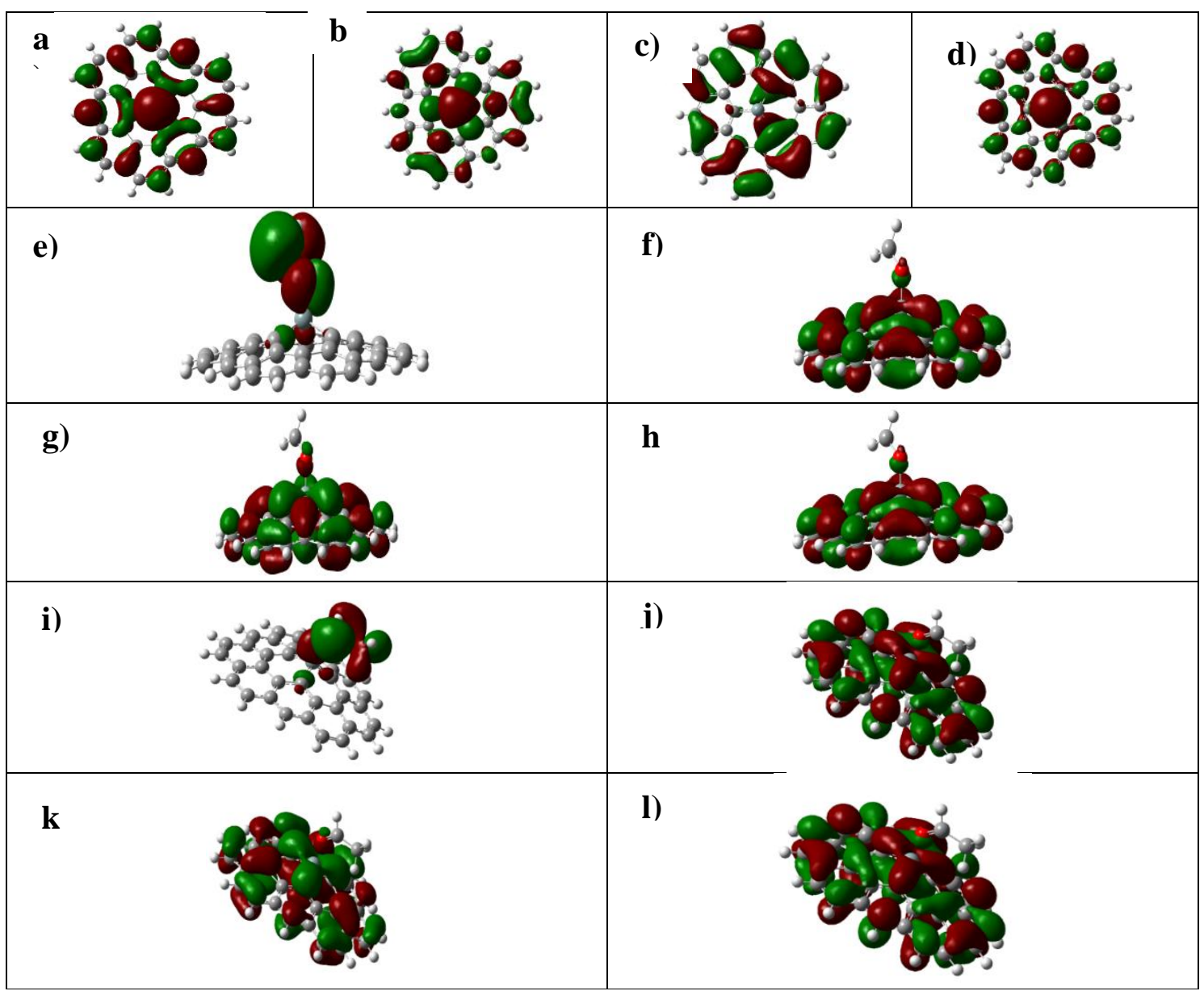

Figure 5. a) Si doped Graphene $\alpha H O M O$ b) Si doped Graphene $\alpha$ LUMO c) Si Doped Graphene $\beta H O M O$ d) Si Doped Graphene $\beta$ HOMO e) Formaldehyde adsorbed Si doped Graphene $\alpha$ HOMO f) Formaldehyde adsorbed Si doped Graphene $\alpha$ LUMO g) Formaldehyde adsorbed Si doped Graphene $\beta$ HOMO h) Formaldehyde adsorbed Si doped Graphene BLUMO i) Acetaldehyde adsorbed Si doped Graphene $\alpha \mathrm{HOMO}$ j) Acetaldehyde adsorbed Si doped Graphene $\alpha$ LUMO k) Acetaldehyde adsorbed Si doped Graphene $\beta$ HOMO 1) Acetaldehyde adsorbed Si doped Graphene $\beta$ LUMO. 


\section{Conclusion}

In this study DFT calculation with hybrid B3LYP method with 6-31G(d,p) basis set is performed for sensor property of Si doped graphene for common indoor contaminants, formaldehyde and acetaldehyde. The charge transfer of formaldehyde is very weak. The charge transfers occur after adsorptions from acetaldehyde molecule to cluster and from cluster to formaldehyde molecule. The HOMO-LUMO gap value has decreased for $\alpha \mathrm{MOs}$, which indicates that it has gained conductivity. The chemical hardness decreased and the chemical potential increased for aMOs after adsorption. Subsequently, these properties prove that the Si element doped graphene structure might be a sensor for the detection of acetaldehyde and formaldehyde molecules.

\section{Acknowledgements}

This paper was prepared within the graduate course (KIM502) of the Chemical Engineering MSc Program in the Graduate School of Natural and Applied Science.

\section{References}

[1] Y. Zou, F. Li, Z. H. Zhu, M. W. Zhao, X. G. Xu, \& X. Y. Su, An ab initio study on gas sensing properties of gşraphene and $\mathrm{Si}$ doped graphene, The European Physical Journal B, 81.4 (2011) 475-479.

[2] Y. Tang, Z. Liu, X. Dai, Z. Yang, W. Chen, D. Ma, \& Z. Lu, Theoretical study on the Sidoped graphene as an efficient metal-free catalyst for $\mathrm{CO}$ oxidation, Applied surface science, 308 (2014) 402-407.

[3] S. G. Chatterjee, S. Chatterjee, A. K. Ray, A. K. Chakraborty, Graphene-metal oxide nanohybrids for toxic gas sensor: a review, Sensors and Actuators B: Chemical, 221 (2015): 1170-1181.

[4] S. S. Varghese, S. Lonkar, K. K. Singh, S. Swaminathan, S., \& A. Abdala, Recent advances in graphene based gas sensors, Sensors and Actuators B: Chemical, 218 (2015) 160-183.

[5] V. E. C. Padilla, M. T. R. de la Cruz, Y. E. Á. Alvarado, R. G. Díaz, C. E. R. García, \& G. H. Cocoletzi, Studies of hydrogen sulfide and ammonia adsorption on $\mathrm{P}$-and Si-doped graphene: density functional theory calculations, Journal of molecular modeling, 25.4 (2019) 94.

[6] Y. Chen, B. Gao, J. X. Zhao, Q. H. Cai, H. G. Fu, Si-doped graphene: an ideal sensor for NO-or NO2-detection and metal-free catalyst for N2O-reduction, Journal of molecular modeling, 18.5 (2012) 20432054.

[7] F. Niu, J. M. Liu, L. M. Tao, W. Wang, \& W. G. Song, Nitrogen and silica co-doped graphene nanosheets for $\mathrm{NO} 2$ gas sensing, Journal of Materials Chemistry A, 1.20 (2013) 6130-6133.

[8] Y. Chen, X. C. Yang, Y. J. Liu, J. X. Zhao, Q. H. Cai, \& X. Z.Wang, Can Si-doped graphene activate or dissociate $\mathrm{O} 2$ molecule?, Journal of Molecular Graphics and Modelling, 39 (2013) 126-132.

[9] T. Tunsaringkarn, T. Prueksasit, D. Morknoy, W. Siriwong, N. Kanjanasiranont, S. Semathong, S., K. Zapaung, Health risk assessment and urinary biomarkers of VOCs exposures among outdoor workers in urban area, Bangkok, Thailand, Int. J. Environ. Pollut. Solut 2 (2014) 32-46.

[10] C. Elosua, I. R. Matias, I. C. Bariain, \& F. J. Arregui, Volatile organic compound optical fiber sensors: A review, Sensors 6.11 (2006) 1440-1465.

[11] S. Guo, C. Mei, $13 \mathrm{C}$ isotope evidence for photochemical production of atmospheric formaldehyde, acetaldehyde, and acetone pollutants in Guangzhou, Environmental chemistry letters, 11.1 (2013) 77-82.

[12] H. Duan, W. Deng, Z. Gan, D. Li, \& D. Li, SERS-based chip for discrimination of formaldehyde and acetaldehyde in aqueous solution using silver reduction, Microchimica Acta, 186.3 (2019) 175.

[13] R. Majidi, and A. R. Karami, Adsorption of formaldehyde on graphene and graphyne. ,

[14] X. Y. Liu, and J. M. Zhang, Formaldehyde molecule adsorbed on doped graphene: a 
first-principles study, Applied surface science, 293 (2014) 216-219.

[15] Beheshtian, J., Ahmadi P., and M. Noei, Sensing behavior of $\mathrm{Al}$ and $\mathrm{Si}$ doped BC3 graphenes to formaldehyde. Sensors and Actuators B: Chemical, 181 (2013) 829834.

[16] Q. Zhou, L. Yuan, X. Yang, Z. Fu, Y. Tang, C. Wang, \& H. Zhang, DFT study of formaldehyde adsorption on vacancy defected graphene doped with $\mathrm{B}, \mathrm{N}$, and S. Chemical Physics, 440 (2014) 80-86.

[17] J. Ye, X. Zhu, B. Cheng, J. Yu \& C. Jiang, Few-layered graphene-like boron nitride: a highly efficient adsorbent for indoor formaldehyde removal, Environmental Science \& Technology Letters, 4.1 (2017) 20-25.

[18] D. Wang, M. Zhang, Z. Chen, H. Li, A. Chen, X. Wang, J. Yang, Enhanced formaldehyde sensing properties of hollow $\mathrm{SnO} 2$ nanofibers by graphene oxide, Sensors and Actuators B: Chemical, 250 (2017) 533-542.

[19] Y. Wang, M. Zhu, L. Kang, \& B. Dai, Density functional theory study of sidechain alkylation of toluene with formaldehyde over alkali-exchanged zeolite, Microporous and mesoporous materials, 196 (2014) 129-135.

[20] X. Chu, T. Hu, F. Gao, Y. Dong, W. Sun, L. Bai, Gas sensing properties of grapheneWO3 composites prepared by hydrothermal method, Materials Science and Engineering: B, 193 (2015) 97-104.

[21] Q. Meng, Y. Shen, J. Xu, X. Ma, \& J. Gong, Mechanistic understanding of hydrogenation of acetaldehyde on Au (111): a DFT investigation, Surface Science, 606.21-22 (2012) 1608-1617.

[22] W. Kohn, L. Sham, Self-consistent equations including exchange and correlation effects, Physical Review Journal Archive 140 (1965) A1133-A1138.

[23] A. T. Bilgiçli, H. G. Bilgiçli, A. Günsel, H. Pişkin, B. Tüzün, M. N. Yarasir, \& M. Zengin, The new ball-type zinc phthalocyanine with SS bridge; Synthesis, computational and photophysicochemical properties, Journal of Photochemistry and
Photobiology A: Chemistry, 389 (2020) 112287.

[24] J. Frisch, G.W. Trucks, H.B. Schlegel, G.E. Scuseria, M.A. Robb, J.R. Cheeseman, G., Gaussian, Inc., Wallingford CT, 2013.

[25] A. D. Becke, Density-functional thermochemistry. III. The role of exact exchange, The Journal of Chemical Physics 98 (1993) 5648.

[26] P. J. Stephens, F. J. Devlin, C. F. Chabalowski, M. J. J. Frisch, J. Phys. Chem. 1994, 98, 11623-11627.

[27] J. Tirado-Rives and W. L. Jorgensen, Performance of B3LYP Density Functional Methods for a Large Set of Organic Molecules , J. Chem. Theory Comput., (2008) 4, 297-306.

[28] S. Thakur, S.M. Borah, N.C. Adhikary, A DFT study of structural, electronic and optical properties of heteroatom doped monolayer graphene, Optik 168 (2018) 228236.

[29] A.S. Rad, First principles study of Al-doped graphene as nanostructureadsorbent for NO2and N2O: DFT calculations, Applied Surface Science 357 (2015) 1217-1224.

[30] A.S. Rad, Adsorption of mercaptopyridine on the surface of Al- and B-doped graphenes: Theoretical study, Journal of Alloys and Compounds 682 (2016) 345351.

[31] D. G. Sangiovanni, G. K. Gueorguiev and A. Kakanakova-Georgieva, $\mathrm{Ab}$ initio molecular dynamics of atomic-scale surface reactions: insights into metal organic chemical vapor deposition of AlN on graphene, Phys. Chem. Chem. Phys. 20 (2018) 17751-17761.

[32] X. Rozanska, R.A. van Santen, F. Hutschka, J. Hafner, A periodic DFT study of intramolecular isomerization reactions of toluene and xylenes catalyzed by acidic mordenite, J. Am. Chem. Soc. 123 (2001) 7655-7667.

[33] A.M. Vos, X. Rozanska, R.A. Schoonheydt, R.A. van Santen, F. Hutschka, J. Hafner, A theoretical study of the alkylation reaction of toluene with methanol catalyzed by acidic 
mordenite, J. Am. Chem. Soc. 123 (2001) 2799-2809.

[34] C. Ricca, F. Labat, C. Zavala, N. Russo, C. Adamo, G. Merino, \& E. Sicilia, B,NCodoped Graphene as Catalyst for the Oxygen Reduction Reaction: Insights from Periodic and Cluster DFT Calculations, Journal of Computational Chemistry, 39.11 (2018): 637-647.

[35] M. F. Fellah, Direct decarbonylation of furfural to furan: A density functional theory stüdy on Pt-graphene Applied Surface Science 405 (2017) 395-404.

[36] C.S. Tautermann and D.C. Clary, Comparative study of cluster- and supercellapproaches for investigating heterogeneous catalysis by electronic structure methods: Tunneling in the reaction $\mathrm{N}+\mathrm{H}-\mathrm{NH}$ on $\mathrm{Ru}(0001)$, Phys. Chem. Chem. Phys., 8 (2006) 1437-1444.

[37] A.S. Rad, D. Zareyee, Adsorption properties of $\mathrm{SO} 2$ and $\mathrm{O} 3$ molecules on Pt-decorated graphene: A theoretical study, Vacuum, 130 (2016) 113-118.

[38] C. Tabtimsai, W. Rakrai, B. Wanno, Hydrogen adsorption on graphene sheets doped with group 8B transition metal: A DFT investigation, Vacuum, 139 (2017) 101-108.

[39] Y. Qin, H.H. Wu, L.A. Zhang, X. Zhou, Y. Bu, W. Zhang, F. Chu, Y. Li, Y. Kong, Q. Zhang, D. Ding, Y. Tao, Y. Li, M. Liu, and X.C. Zeng, Aluminum and Nitrogen Codoped Graphene: Highly Active and Durable Electrocatalyst for Oxygen Reduction Reaction, ACS Catalysis, 9 (2019) 610-619.

[40] C. Tabtimsai, W. Rakrai, B. Wanno, Hydrogen adsorption on graphene sheets doped with group 8B transition metal: A DFT investigation, Vacuum, 139 (2017) 101-108.

[41] M. Malček, L. Bučinský, F. Teixeira, M. Natália, D. S. Cordeiro, Detection of simple inorganic and organic molecules over $\mathrm{Cu}$ decorated circumcoronene: a combined DFT and QTAIM study, Phys. Chem. Chem. Phys., 20 (2018) 16021-16032.

[42] J.B. Foresman, Æ. Frisch, Exploring Chemistry with Electronic Structure
Methods, 2nd ed., Gaussian Inc., Pittsburgh, PA, (1996) 68-69.

[43] R.G. Pearson, Chemical hardness and density functional theory, J. Chem. Sci., 117 (2005) 369-377.

[44] R.G. Pearson, The electronic chemical potential and chemical hardness, Journal of Molecular Structure THEOCHEM, 255 (1992) 261-270

[45] B. Tüzün, Investigation of pyrazoly derivatives schiff base ligands and their metal complexes used as anti-cancer drug., Spectrochimica Acta Part A: Molecular and Biomolecular Spectroscopy, 227 (2020) 117663.

[46] V. Nagarajan, \& R. Chandiramouli, DFT investigation of formaldehyde adsorption characteristics on $\mathrm{MgO}$ nanotube. Journal of Inorganic and Organometallic Polymers and Materials, 24.6 (2014) 1038-1047.

[47] M. Noei, \& A. A. Peyghan, A DFT study on the sensing behavior of a $\mathrm{BC} 2 \mathrm{~N}$ nanotube toward formaldehyde, Journal of molecular modeling, 19.9 (2013) 3843-3850.

[48] Y. Kurosaki, \& K. Yokoyama, (2002). Photodissociation of acetaldehyde, $\mathrm{CH} 3 \mathrm{CHO} \rightarrow \mathrm{CH} 4+\mathrm{CO}$ : direct ab initio dynamics study, The Journal of Physical Chemistry A 106.47 (2002) 11415-11421.

[49] R. Gholizadeh, \& Y. X. Yu, N2O+ CO reaction over $\mathrm{Si}$-and $\mathrm{Se}$-doped graphenes: an ab initio DFT study, Applied Surface Science 357 (2015) 1187-1195.

[50] S. F. Rastegar, A. A. Peyghan, \& N. L Hadipour, Response of Si-and Al-doped graphenes toward $\mathrm{HCN}$ : a computational study, Applied surface science 265 (2013) 412-417.

[51] M. D. Esrafili, N. Saeidi, \& P. Nematollahi, Si-doped graphene: A promising metal-free catalyst for oxidation of SO2, Chemical Physics Letters, 649 (2016)37-43.

[52] M. D. Esrafili, N. Saeidi, \& P. Nematollahi, A DFT study on $\mathrm{SO} 3$ capture and activation over Si-or Al-doped graphene, Chemical Physics Letters, 658 (2016) 146-151.

[53] Z. Mohsenpour, E. Shakerzadeh, \& M. Zare, Quantum chemical description of formaldehyde (HCHO), acetaldehyde $(\mathrm{CH} 3 \mathrm{CHO})$ and propanal $(\mathrm{CH} 3 \mathrm{CH} 2 \mathrm{CHO})$ 
pollutants adsorption behaviors onto the bowl-shaped B 36 nanosheet, Adsorption, 23.7-8 (2017) 1041-1053.

[54] A. Ahmadi, N. L. Hadipour, M. Kamfiroozi, \& Z. Bagheri, Theoretical study of aluminum nitride nanotubes for chemical sensing of formaldehyde, Sensors and Actuators B: Chemical 161.1 (2012) 1025 1029.

[55] Y. Yong, H. Jiang, X. Lv, J. Cao, The cluster-assembled nanowires based on $\mathrm{M} 12 \mathrm{~N} 12(\mathrm{M}=\mathrm{Al}$ and $\mathrm{Ga})$ clusters as potential gas sensors for $\mathrm{CO}, \mathrm{NO}$, and $\mathrm{NO} 2$ detection, Physical Chemistry Chemical Physics, 18 (2016) 21431-21441.

[56] N. L. Hadipour, H. Soleymanabadi, A. A. Peyghan, Theoretical study on the Al-doped $\mathrm{ZnO}$ nanoclusters for $\mathrm{CO}$ chemical sensors, The Journal of Physical Chemistry C, 119 (2015) 6398-6404.

[57] E.D. Glendering, A.E. Reed, J.E. Carpenter, F. Weinhold, NBO Version 3.1, TCI, University of Wisconsin, Madison. 